\title{
Comparative Study of Ceramic-to-Metal Bonding
}

\author{
Juliano Milczewsky SCOLARO ${ }^{1}$ \\ Jefferson Ricardo PEREIRA ${ }^{2}$ \\ Accácio Lins do VALLE ${ }^{3}$ \\ Gerson BONFANTE ${ }^{3}$ \\ Luiz Fernando PEGORARO3
}

\author{
${ }^{1}$ Department of Prosthodontics, Paulista University, UNIP, Goiânia, GO, Brazil \\ ${ }^{2}$ Department of Prosthodontics, School of Dentistry of Passo Fundo, University of Passo Fundo, Passo Fundo, RS, Brazil \\ ${ }^{3}$ Department of Prosthodontics, School of Dentistry of Bauru, University of São Paulo, Bauru, SP, Brazil
}

\begin{abstract}
Dentists and technicians have used dental ceramics associated with different types of alloys without taking into account the characteristics of compatibility of these materials. Knowing the properties of the alloy and ceramic used in metal/ceramic restorations is a key factor for treatment success. The purpose of this study was to evaluate the bond strength of a palladium-silver alloy (Pors-on 4) to 3 ceramics (Ceramco, Noritake and Vita VMK-68) using shear forces at the metal-ceramic interface. A stainless steel cylindrical matrix was used for preparation of the metal dies, application of ceramic and shear strength testing. Thirty palladium-silver alloy cylinders received two layers of opaque and two layers of body porcelain, and shear tests were performed in a universal testing machine at a cross-head speed of $0.5 \mathrm{~mm} / \mathrm{min}$. Shear bond strength means (in MPa) were: 28.21(Ceramco), 28.96 (Noritake) and 24.11 (Vita VMK-68). One-way ANOVA did not show statistically significant differences ( $>>0.05)$ among the materials. The results of this study indicate that the three evaluated ceramic systems are suitable to be used in combination with the tested palladium-silver alloy.
\end{abstract}

Key Words: Metaloceramic restorations, alloys, ceramics, compressive strength.

\section{INTRODUCTION}

Since its introduction in the 1950 's, porcelainfused-to-metal restorations have played an important role in restorative dentistry because they are able to combine a great color stability with resistance provided by the metal framework. Over the past years, several authors have emphasized the importance of evaluating different alloys and ceramics using physical tests (1-7), which have been designed (4-8) to reproduce the complex set of forces that act on the metal-ceramic interface (8-12). In view of this, there has been an increased interest on the assessment of metaloceramic bond strength, seeking the test that is closest to the ideal and can simulate oral conditions as reliably as possible. Several tests have been used to evaluate properties such as color stability (4), shear (7), tensile (6), flexural (10) and torsional strength (13).
According to Anusavice (3), a test must fulfill two primary requirements to provide accurate results: firstly, stresses concentration must take place only along the interface because if stresses are concentrated outside the interface (e.g., at the end of the ceramic layer), the results will be lower than the actual metalceramic bond strength; secondly, the amount of tension should be zero because if this type of force exists, it is likely that the ceramic fractures and the test results become "contaminated".

The circular-planar surface shear test proposed by Chong et al. (7) provides easy specimen fabrication and standardization. Furthermore, the matrix used for specimen preparation is specific for shear testing. According to the requirements described by these authors $(6-8,11,12)$, this test is highly reliable because the metal-ceramic interface bonding is the only type of adhesion present. 
Palladium alloys were introduced in the 1980's and proved suitable for dental purposes $(9,12,14-16)$. This type of alloy has particularities that, in spite of not interfering with porcelain-metal union, should not be overlooked. The main path for bonding with these alloys is mechanical and such condition has not produced significant clinical failures (3). However, there are other elements in the alloy composition such as silver and tin, which are susceptible to oxidation. Therefore, previous oxidation is an important procedure that may increase the bond strength at metal-ceramic interface $(9,12,15$ 18). Previous oxidation has been shown to result in emergence of silver nodules that can undergo volatilization $(9,12,16-18)$, On the other hand, the presence of silver vapors may cause ceramic spotting or darkening.

Another characteristic of palladium alloys is their high sensitivity to the presence of carbon during the casting procedures, which may generate problems like ceramic porosities and carbon contamination in the alloy $(9,12,13,15)$. Carbon leads to formation of carbon monoxide during ceramic baking, originating bubbles and porosities that can cause cracks or fractures.

In view of the continuous development of dental porcelains and the increasingly widespread use of palladium alloys, the aim of this study was to evaluate the shear bond strength of a palladium-silver alloy (Pors-on 4) to 3 ceramics (Ceramco, Noritake and Vita VMK-68).

\section{MATERIAL AND METHODS}

A cylindrical stainless steel matrix (Fig. 1 A-D) was used for specimen preparation. The same matrix was used for ceramic layering and shear strength testing. The matrix had a central hole with $6.5 \mathrm{~mm}$ in depth and $6.0 \mathrm{~mm}$ in diameter, and an auxiliary $2.0-\mathrm{mm}$ diameter perforation across the matrix (Fig. 1-B) up to the bottom of the central perforation, which was used to remove the dies and specimens using a metallic pin (Fig. 1-C). The set of matrix components also includes a metallic base (Fig. 1-A) to which the matrix was screwed to adapt to the testing machine and a disc (6.0 $\mathrm{mm}$ in diameter; $1.5-\mathrm{mm}$ thick) used as a spacer to standardize the ceramic layer thickness (Fig. 1-D).

The wax patterns were made with the disc positioned inside the perforation. The wax (Green Regular Wax; Kota Ind. Ltd., São Paulo, SP, Brazil) was liquefied at $75^{\circ} \mathrm{C}$ and flowed with the aid of a dropper into the perforation. After wax cooling, the patterns were removed by the introduction of the metallic pin in the auxiliary perforation and stored in water until the investment and casting procedures.

Thirty metallic dies were obtained using a palladium-silver alloy (Pors-on 4, Degussa S.A., São Paulo, $\mathrm{SP}$, Brazil). The investment and casting procedures were performed as per manufacturer's specifications.

After checking the adaptation to the matrix, the metallic cylinders were ultrasonicated, washed in distilled water, sandblasted with $50-\mu \mathrm{m}$ aluminum oxide and oxidized according to the manufacturer's instructions. The specimens were washed in distilled water, dried and kept untouched until ceramic application. They were "coated" with 3 ceramics: Ceramco (Ceramco Inc., Burlington, NJ, USA), Noritake Super Porcelain EX-3 (Noritake Kizai Co., Ltd., Nagoia, Japan) and Vita VMK-68 (Vita Zahnfabrik, Säckingen, Germany). Ten metallic cylinders were used for each ceramic brand.

Each metallic die was positioned inside the perforation, without the disc, leaving a $1.5-\mathrm{mm}$ space for

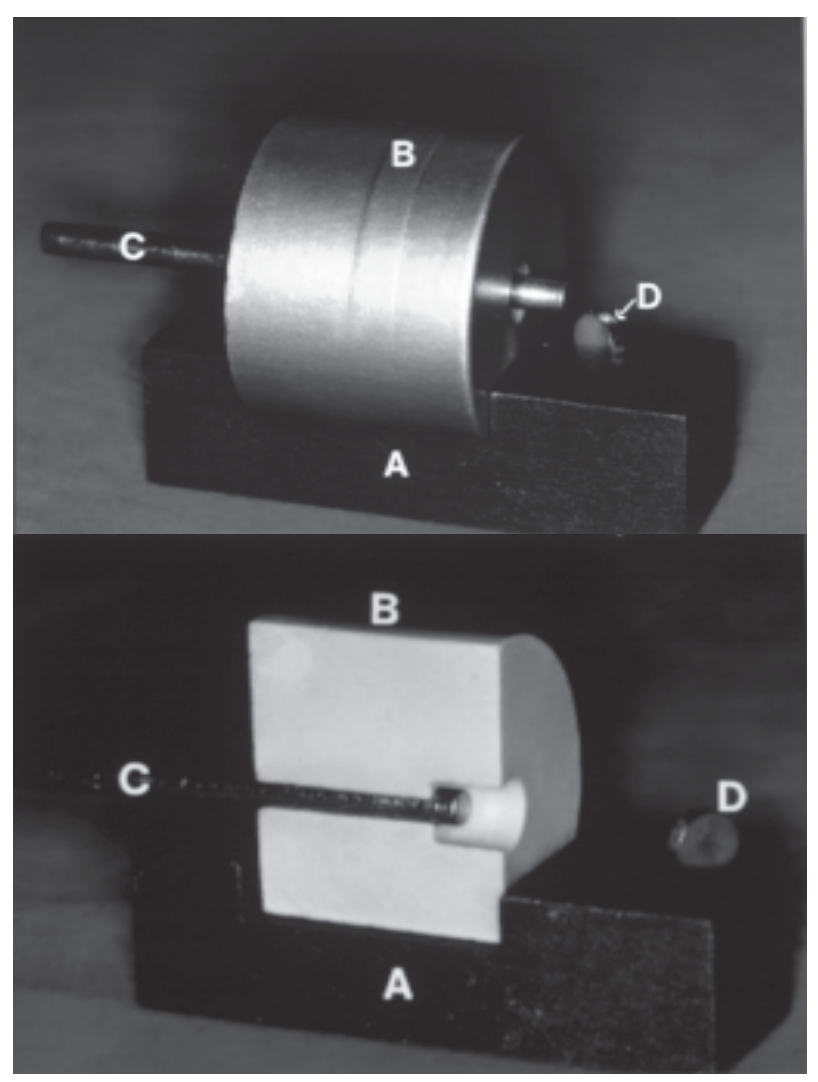

Figure 1. Matrix's set components. A= Base; $\mathrm{B}=$ Matrix; $\mathrm{C}=$ Pin - specimen removal; $\mathrm{D}=$ Spacer disk. 
ceramic application. Ceramics were applied as per manufacturer's instructions for mass preparation, condensing, baking temperature and time. After porcelain application, the specimens were positioned into the matrix with the disc at the bottom of the perforation, leaving the ceramic layer visible outside the matrix, in such a way that the shear forces could be applied only at metal/ceramic interface. Shear strength testing was performed in a universal testing machine (Kratos 2000; Kratos Dynamometers, São Paulo, SP, Brazil) with a $0.5-\mathrm{mm}$ thick bevel-shaped rod at a crosshead speed of $0.5 \mathrm{~mm} / \mathrm{min}$ until failure (Fig. 2). Bond strengths (in $\mathrm{MPa}$ ) at metal-ceramic interface were recorded. Failure modes were examined with a stereoscopic microscope (Nikon SMZ10, Tokyo, Japan) at $\times 10$ magnification.

Data were analyzed statistically by one-way ANOVA at 5\% significance level.

\section{RESULTS}

Shear bond strength means $( \pm \mathrm{SD})$ for each ceramic were the following: Noritake $(28.96 \pm 6.92)$, Ceramco $(28.20 \pm 8.65)$ and Vita VMK $68(24.11 \pm$ 6.27). No statistically significant differences were observed among the materials $(p>0.05)$. Modes of failure were most predominantly adhesive (27 out of 30 specimens). The other 3 specimens had mixed failures (adhesive and cohesive).

\section{DISCUSSION}

There is still no test that can be considered as ideal

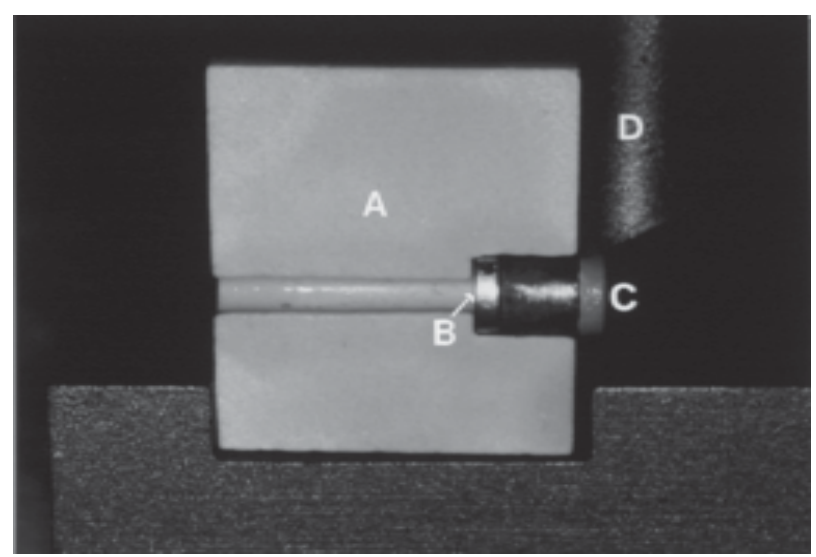

Figure 2. Schematic view of the shear strength test. $\mathrm{A}=$ Matrix; $\mathrm{B}$ $=$ Spacer disk in position; $\mathrm{C}=$ Ceramic portion; $\mathrm{D}=$ Active point. for assessment of shear bond strength at metal-ceramic interface. Several tests have been done with specimens obtained from ceramic application around metallic patterns in a semi-circle shape or over a flat metal surface, in order to avoid tensions on ceramic. However, these shear strength tests have been criticized because of the influence of metal surface texture and the possible effect of residual stress from mismatches of thermal expansion or the hoop-stress phenomenon (11).

In this study, the circular-planar interface shear test was used with a specifically designed matrix for allowing easy fabrication and standardization of specimens $(7,11)$. This type of test has been considered as highly reliable because it is based on minimal experimental variables and least residual stresses at metalceramic interface $(7,11)$.

Chong et al. (7), using the same type of shear testing for evaluation of Ni-Cr alloys, obtained bond strengths of around $30 \mathrm{MPa}$. Other authors $(8,11,17)$ using the same test type with slight methodological alterations, found bond strengths of 15 to $60 \mathrm{MPa}$. It can be inferred from these findings that even when a similar bond strength test is used, the results can vary greatly due mainly to the lack of methodology standardization for evaluation of porcelain-fused-to-metal union.

In this study, there was no significant differences among the tested ceramics $(p=0.299)$. Clinically, the interpretation of these results suggests that all ceramics present sufficient bond strength and can be used routinely. It has been reported $(3,7,11,12,15)$ that shear bond strength means greater than $10 \mathrm{MPa}$ indicate clinically satisfactory results, representing a higher bond strength value than that required to cause the clinical flaw of metal-ceramic union.

The adhesive failure pattern was predominantly observed. Only $1 \%$ of the specimens had mixed fractures (adhesive/cohesive). Although small ceramic portions remained adhered to the metal surface, a cohesive failure is characterized when the ceramic portion remains adhered to the whole extension of the metal surface and the fracture line travels the portion of "body" porcelain $(10,15)$. According to previous studies $(7,9,10,12)$, the presence of these porcelain "islets" can be considered as an undesirable result of the test type, and not as cohesive fracture.

Previous oxidation procedures may give rise to silver nodules emergence, which promotes adhesion, but can undergo volatilization. The presence of silver 
vapors may, on the other hand, lead to spotting or darkening of the porcelain layer. Such outcomes were not observed in this study. In addition, the use of a ceramic-based investment prevented any superficial contamination of the metal by carbon.

Ceramics have been continuously improved, which has led to increasingly greater strength when they are submitted to a wide range of tests and has decreased failure occurrence remarkably. However, high-quality ceramometal union depends on a properly shaped framework to allow the application of a uniform ceramic layer thickness in order to support only compressive forces. These compressive forces will provide an additional resistance. Although the main cause of failure of porcelain-fused-to-metal restorations is attributed to secondary caries, the success of this type of prosthetic work depends greatly on the bond strength between metal and ceramic. The Pd-Ag alloy evaluate in this study (Porson 4; Degussa) has much smaller grains than other PdAg alloys, which provides better mechanical qualities in addition to a larger external contact surface (15).

Success of porcelain-fused-to-metal restorations depend fundamentally on the union ability between the two materials that should not undergo fatigue or fracturing under different conditions. The ceramic systems evaluated in this study presented similar shear bond strength to each other are suitable for use in combination with the tested palladium-silver alloy.

\section{RESUMO}

Muitos profissionais utilizam restaurações metalocerâmicas sem atentarem para as características de compatibilidade entre metale cerâmica, fator muito importante para o sucesso deste tipo de restauração. Este estudo avaliou a resistência de união entre uma liga de paládio-prata (Pors-on 4) e 3 cerâmicas (Ceramco, Noritake e Vita VMK-68) aplicando-se forças de cisalhamento na interface metal/porcelana. Uma matriz especialmente desenvolvida serviu para a confecção dos corpos-de-prova e realização dos testes de cisalhamento. Trinta corpos-de-prova foram confeccionados, com duas camadas de cerâmica opaca e de corpo, e os testes realizados em máquina universal de ensaios $(0,5 \mathrm{~mm} / \mathrm{min})$. As médias de resistência de união (em MPa) foram: 28,21 (Ceramco), 28,96 (Noritake) e 24,11 (Vita VMK-68). A análise de variância a um critério não demonstrou diferença estatisticamente significante entre os materiais $(p>0,05)$. Os resultados demonstraram que todas as cerâmicas foram compatíveis com a liga avaliada.

\section{REFERENCES}

1. Brecker SC. Porcelain baked to gold - a new medium in Prosthodontics. J Prosthet Dent 1956;6:801-810.

2. Stavridakis MM, Papazoglou E, Seghi RR, Johnston WM, Brantley WA. Effect of different high-palladium metalceramic alloys on the color of opaque and dentin porcelain. J Prosthet Dent 2004;92:170-178.

3. Anusavice KJ. Noble metal alloys for metal-ceramic restorations. Dent Clin N Amer 1985;29:789-803.

4. Kourtis SG, Tripodakis AP, Doukoudakis AA. Spectrophotometric evaluation of the optical influence of different metal alloys and porcelains in the metal-ceramic complex. J Prosthet Dent 2004;92:477-485.

5. Kellerhoff RK, Fischer J. In vitro fracture strength and thermal shock resistance of metal-ceramic crowns with cast and machined AuTi frameworks. J Prosthet Dent 2007;97:209-215.

6. Sced IR, Mclean JW. The strength of metal/ceramic bonds with base metals containing chromium. Brit Dent $\mathrm{J}$ 1972;32:232-234.

7. Chong MP, Beech D, Chem C. A simple shear test to evaluate the bond strength of ceramic fused to metal. Aust Dent J 1980;25:357-361.

8. Suansuwan N, Swain MV. New approach for evaluating metalporcelain interfacial bonding. Int J Prosthodont 1999;12:547552.

9. Mackert JR, Ringle RD, Fairhurst CW. High-temperature behavior of a Pd-Ag alloy for porcelain. J Dent Res 1983;62:1229-1235.

10. Mackert JR, Parry EE, Hashinger DT, Fairhust CW. Measurement of oxide adherence to PFM alloys. J Dent Res 1984;63:1335-1340.

11. Hammad IA, Talic YF. Designs of bond strength tests for metal-ceramic complexes: review of the literature. J Prosthet Dent 1996;75:602-608.

12. Papazoglou E, Brantley WA, Johnston WM, Carr AB. Effects of dental laboratory processing variables and in vitro testing medium on the porcelain adherence of high-palladium casting alloys. J Prosthet Dent 1998;79:514-519.

13. Herø H, Syverud M. Carbon impurities and properties of some palladium alloys for ceramic veneering. Dent Mater 1985;1:106-110.

14. Papazoglou E, Brantley WA, Johnston WM. Evaluation of high-temperature distortion of high-palladium metal-ceramic crowns. J Prosthet Dent 2001;85:133-140.

15. Böning K, Walter M. Palladium alloys in prosthodontics: selected aspects. Int Dent J 1990;40:289-297.

16. Viennot S, Lissac M, Malquarti G, Dalard F, Grosgogeat B. Influence of casting procedures on the corrosion resistance of clinical dental alloys containing palladium. Acta Biomater 2006;2:321-330.

17. Hautaniemi JA, Juhanoja JT, Suoninen EJ, Yli-Urpo AU. Oxidation of four palladium-rich ceramic fusing alloys. Biomater 1990;11:62-72.

18. Wu Y, Moser JB, Jameson LM, Malone WF. The effect of oxidation heat treatment on porcelain bond strength in selected base metal alloys. J Prosthet Dent 1991;66:439-444.

\section{ACKNOWLEDGEMENTS}

Accepted July 15, 2007

This study was supported by FAPESP (grant \#98/06880-0). 